\title{
POLÍTICA NACIONAL DE RESÍDUOS SÓLIDOS E SUA IMPLEMENTAÇÃO NO MUNICÍPIO DE RIO POMBA/MG
}

\author{
G. V. SILVA ${ }^{1 *}$, A. R. OLIVEIRA ${ }^{2}$, T. A. SILVA ${ }^{1}$ e P. V. SILVA E FIDELIS ${ }^{1}$ \\ ${ }^{1}$ Instituto Federal do Sudeste de Minas Gerais - Campus Rio Pomba \\ ${ }^{2}$ Universidade Federal de Viçosa - UFV \\ gustavo.silva@ifsudestemg.edu.br*
}

Artigo submetido em janeiro/2015 e aceito em janeiro/2016

DOI: $10.15628 /$ holos .2016 .2697

\section{RESUMO}

Este artigo objetiva analisar a implementação da Política Nacional de Resíduos Sólidos no Município de Rio Pomba/MG, em atendimento ao que dispõe a Constituição da República Federativa do Brasil de 1988 a respeito do direito fundamental ao meio ambiente ecologicamente equilibrado. O equilíbrio ecológico é, portanto, imprescindível para uma sobrevivência digna. De fato, qualquer intercorrência negativa no meio ambiente afeta, desfavoravelmente, a qualidade de vida das pessoas. Para tanto, almeja-se verificar se está sendo assegurada a salubridade pública e ambiental, a través da disposição final dos resíduos sólidos. A questão dos resíduos nos Municípios é pouco conhecida. Assim, pretende-se verificar como está sendo implantada a referida política e compará-la com as disposições legais. Desta forma, os resultados instruirão os atores envolvidos na questão ambiental, a fim de que busquem assegurar serviços públicos eficientes.

PALAVRAS-ChAVE: Meio Ambiente, Política Pública, Poder Público Municipal.

\section{NATIONAL POLICY OF SOLID WASTE AND YOUR IMPLEMENTATION IN THE MUNICIPALITY OF RIO POMBA/MG}

\begin{abstract}
This article aims to analyze the implementation of the National Policy on Solid Waste in the Municipality of Rio Pomba/MG, in compliance with the provisions the Constitution of the Federative Republic of Brazil from 1988 to respect the fundamental right to an ecologically balanced environment. The ecological balance is therefore essential for a dignified survival. In fact, any negative complications in the environment affects
\end{abstract}

adversely the quality of life. For this, it aimed to see if it is assured the public and environmental health, through the disposal of solid waste. The issue of waste in the municipalities is not well known. We intend to check how it is being implemented the policy and compare it with the legal provisions. In this way, the results will instruct the actors involved in environmental issues in order to striving to ensure efficient public services.

KEYWORDS: Environment, Public Policy, Municipal Government. 


\section{INTRODUÇÃO}

A preocupação com a tutela do meio ambiente nasce a partir do momento em que a sua degradação começa a ameaçar não somente o bem estar, mas a própria sobrevivência humana. Muitas pessoas ainda não se deram conta dos problemas advindos da reiterada deterioração ambiental, fazendo com que o planeta se torne a cada dia mais inabitável.

Certo é que o equilíbrio ecológico é imprescindível para uma sobrevivência digna. De fato, qualquer intercorrência negativa no meio ambiente afeta, desfavoravelmente, a qualidade de vida das pessoas. Ademais, é sabido que este direito deve ser garantido pelo Estado, e que, segundo Kelsen (1998) o Estado atua apenas através de seus órgãos, o que denota que a ordem jurídica pode ser criada e aplicada apenas por indivíduos designados pela própria ordem.

Desta forma, uma das grandes aliadas à concretização da salubridade ambiental se denomina políticas públicas, que podem ser compreendidas como:

[...] sistema de decisões públicas que dirige as ações ou omissões, designada a manter ou modificar a realidade de um ou vários setores da vida social, através da fixação de objetivos e estratégias de atuação e da distribuição de recursos necessários para atingir os objetivos estabelecidos (SARAVIA, 2006, p. 29).

As políticas públicas ainda podem ser concebidas como a totalidade de ações, metas e planos que os governos traçam para atingir o bem estar da sociedade e o interesse público, que deve sempre prevalecer sobre o privado.

O primeiro documento legal pátrio que estabeleceu os objetivos, as ações e os instrumentos e que deu ao Brasil as bases de uma política pública ambiental e várias definições foi a Lei no 6.938, de 31/08/81, conhecida como Política Nacional do Meio Ambiente - PNMA, que previu, dentre outros objetivos, a compatibilização do desenvolvimento econômico social com a preservação da qualidade do meio ambiente e do equilíbrio ecológico.

A Lei no 6.938/81, em seu artigo 3으, inciso I, conceitua o meio ambiente, como "o conjunto de condições, leis, influências e interações de ordem física, química e biológica, que permite, abriga e rege a vida em todas as suas formas" (BRASIL, 2014).

Também reconhecendo a importância de se viver em um ambiente saudável, a Constituição da República Federativa do Brasil de 1988 (CF/88) foi a primeira a se preocupar de maneira específica com a proteção ambiental, inclusive em capítulo próprio (Capítulo VI - Do Meio Ambiente, art. 225), sendo que as Constituições anteriores sequer empregaram a expressão meio ambiente em seus textos.

O artigo 225, caput, da Constituição Federal de 1988, dispõe:

Todos têm direito ao meio ambiente ecologicamente equilibrado, bem de uso comum do povo e essencial à sadia qualidade de vida, impondo-se ao Poder Público e à coletividade o dever de defendê-lo e preservá-lo para as presentes e futuras gerações (BRASIL, 2014, p. 67).

Cumpre ressaltar que o direito ao meio ambiente ecologicamente equilibrado é um direito fundamental, podendo este ser entendido como o que visa garantir uma convivência digna, livre e igual para todas as pessoas. 
A Carta Magna criou um novo "direito constitucional fundamental ao meio ambiente saudável. Como todo direito fundamental, o direito ao ambiente ecologicamente equilibrado é indisponível" (MILARÉ, 2005, p. 187).

Referido direito foi concebido, primeiramente, no âmbito da Conferência das Nações Unidas sobre o Ambiente Humano de 1972, na Declaração de Estocolmo, sendo reafirmado pela Declaração do Rio de Janeiro sobre Meio Ambiente e Desenvolvimento de 1992, pela Carta da Terra de 1997 e, recentemente, pela Conferência das Nações Unidas sobre o Desenvolvimento Sustentável (Rio+20).

Cabe esclarecer que "a consciência ambientalista propiciou o surgimento e o desenvolvimento de uma legislação ambiental em todos os países, variada, dispersa e frequentemente confusa" (MATEO, 1977 apud SILVA, 2009, p. 34).

Em decorrência da existência de uma multiplicidade de normas de cunho ambiental, como dito, às vezes confusas, a aplicação das mesmas tornou-se uma tarefa árdua, inclusive no que se refere à criação e funcionamento dos organismos incumbidos pela proteção do meio ambiente. Mas tal fato, não pode servir de embasamento para o reiterado descumprimento das leis ambientais, eis que o meio ambiente equilibrado é essencial à sadia qualidade de vida.

O legislador constituinte previu o direito fundamental ao ambiente equilibrado, sendo que foram instituídas diversas normas jurídicas visando conferir efetividade a este direito, como é o caso da Lei no 12.305, de 2 de agos to de 2010, que instituiu a Política Nacional de Resíduos Sólidos (PNRS), alterou a Lei no 9.605, de 12 de fevereiro de 1998 e previu outras providências, tratandose de uma importante norma jurídica que, acredita-se contribuir com a redução dos gravíssimos prejuízos ambientais advindos da disposição inadequada dos resíduos sólidos (ANTUNES, 2011).

OBS Para tanto, a PNRS estabelece os princípios, objetivos e instrumentos, bem como as diretrizes relativas à gestão integrada e ao gerenciamento de resíduos sólidos, incluídos os perigosos, as responsabilidades dos geradores e do poder público e os instrumentos econômicos aplicáveis.

A referida Lei, caso seja implementada de forma eficiente e eficaz, poderá contribuir incisivamente para a mitigação dos efeitos adversos causados ao meio ambiente pela disposição inadequada dos resíduos sólidos.

Muito embora existam diversas regras jurídicas prevendo o direito ao ambiente equilibrado, fato é que muitos Municípios não possuem estrutura física e/ou pessoal para conferir a execução plena de algumas delas, como por exemplo, ao não proporcionar tratamento adequado dos efluentes, dos resíduos industriais e domésticos, omitirem-se com relação a obras irregulares.

O Município de Rio Pomba é considerado de pequeno porte, sendo indiscutível que seria mais fácil cuidar dos seus problemas ambientais do que das grandes cidades, a uma porque os danos vistos em seu território é proporcionalmente menor, a duas porque os órgãos encarregados da execução da política ambiental têm mais facilidade de identificar e controlar referidos prejuízos nos pequenos Municípios, e a três porque os custos empregados na proteção e até mesmo na recuperação do meio ambiente são bem inferiores.

Lado outro, é cediço que os órgãos públicos devem pautar a prestação de serviços no princípio da eficiência, a fim de atender aos anseios da população.

Neste contexto, sobre o papel das organizações públicas, pode-se dizer que: 
As organizações públicas - responsáveis pela prestação de serviços para a sociedade - podem ser aceitas como sistemas complexos, interdependentes e dinâmicos. [...] Buscam, no cumprimento de suas atividades, alcançar o melhor desempenho possível e, assim, atender de maneira efetiva e com qualidade as demandas da população (MATIAS-PEREIRA, 2010, p. 78).

Cabe salientar que a existência de discrepâncias entre as demandas sociais e a capacidade das organizações públicas em atendê-las, tendem a gerar um hiato de ações entre o que se busca e o que se realiza. É importante procurar entender os fatores que intermedeiam esse processo.

A Carta Magna distribuiu as competências entre os entes federados da seguinte maneira: enumeração dos poderes da União, poderes remanescentes para os Estados e poderes definidos indicativamente para os Municípios.

A União possui superioridade no que se refere à tutela do meio ambiente. Compete a ela a Política Geral do Meio Ambiente, o que foi concretizado pela Lei no 6.938/81 - Política Nacional do Meio Ambiente. Também Ihe cumpre instituir o Sistema Nacional de Gerenciamento de Recursos Hídricos e definir critérios de outorga de direitos de seu uso e legislar sobre águas e energia.

A CF/88 preceitua no art. 23 sobre a competência material comum da União, dos Estados, do Distrito Federal e dos Municípios para a prestação dos serviços previstos nos respectivos incisos.

A competência legislativa concorrente se encontra no art. 24 que preceitua caber à União, aos Estados e ao Distrito Federal legislar concorrentemente sobre florestas, caça, pesca, dentre outros. Neste papel, a União estabelece normas gerais e os Estados, normas suplementares.

Os Estados não possuem competência exclusiva em matéria ambiental, mas comum com a União e Municípios, consoante determina o art. 23, incisos III, IV, VI e VII, CF/88. Contudo, possuem competência legislativa suplementar de normas gerais estabelecidas pela União, nos termos do art. 24, VI, VII, VIII e seu $\S 2^{\circ}, \mathrm{CF} / 88$.

Por sua vez, os Municípios também são dotados de competência na área ambiental, a qual está prevista no art. 23, III, IV, VI e VII, CF/88 em comum com a União e os Estados. Além disso, detêm atribuições para legislarsobre: assuntos de interesse local; suplementar a legislação federal e estadual e promover, no que couber, adequado ordenamento territorial.

Estudos desta natureza se revelam importantes em razão da situação local da salubridade ambiental e dos resíduos sólidos ser pouco conhecida, devendo ser atribuída a merecida relevância a este tema. Assim, esta pesquisa objetiva fornecer subsídios para tais questões no Município de Rio Pomba/MG.

Desta forma, será verificada a estrutura física e de pessoal existente no Município que se relacionam diretamente com o tratamento dos resíduos sólidos, bem como será apontada como é efetuada a repartição constitucional de competências em matéria ambiental e apresentadas as particularidades verificadas na implementação da PNRS no citado Município.

\section{MATERIAIS E MÉTODOS}

Aqui O Município de Rio Pomba/MG, local onde foi realizada esta pesquisa, possui uma área territorial de $252,41 \mathrm{Km}^{2}$ e uma população de 17.110 habitantes, sendo que se situa na mesorregião da zona da mata mineira, na microrregião de Ubá/MG. O bioma em que se encontra é o da Mata Atlântica (IBGE, 2010). 
A questão ambiental no Município de Rio Pomba é tratada pela Lei Orgânica, pelo Código de Posturas Municipais e por algumas Leis Ordinárias, sendo que este trabalho possui como foco a análise da implementação da Lei Federal no 12.305/2010, que foi instituída com a finalidade de conferir efetividade ao preceito constitucional que trata do ambiente ecologicamente equilibrado, logo, da saúde ambiental.

Para a classificação deste trabalho, utilizou-se o critério proposto por Vergara (2010), que o divide em dois grupos: quanto aos fins e quanto aos meios.

Quanto aos fins é descritivo e explicativo. Descritivo, porque visa expor percepções dos servidores dos órgãos analisados, a respeito do possível descumprimento do preceito legal. Explicativo, porque objetiva esclarecer os motivos que levam à ineficiência dos serviços prestados pelos órgãos incumbidos pela tutela ambiental.

Quanto aos meios, é de campo, documental e bibliográfico. É de campo, porque coletou dados nos órgãos que cuidam direta ou indiretamente da política ambiental do Município citado. Documental, porque se utilizaram documentos conservados no interior dos órgãos de tutela ambiental que digam respeito ao objeto de estudo. Bibliográfico, porque se recorreu ao uso de material acessível ao público em geral, como revistas, jornais, livros e redes eletrônicas.

Foram utilizados dados primários e secundários. Os primários foram obtidos por meio de entrevistas aos Secretários de Obras, de Governo, de Administração, do Chefe do Departamento de Contabilidade, do responsável pela Secretaria de Meio Ambiente, do Presidente do Conselho Municipal de Defesa do Meio Ambiente - CODEMA e do Setor Jurídico da Prefeitura Municipal de Rio Pomba/MG. Os secundários foram obtidos a partir de documentos disponibilizados pelos representantes acima.

Os documentos e as entrevistas foram apreciados por meio da técnica de análise de conteúdo, a qual "[...] refere-se ao estudo de textos, documentos e verbalizações orais. É uma técnica de análise de comunicações, tanto associada aos significados, quanto aos significantes da mensagem" (VERGARA, 2010, p. 5).

Ainda nesta direção Bardin (1997, p. 42) ensina que a análise de conteúdo compreende:

[...] um conjunto de técnicas de análise das comunicações visando obter, por procedimentos, sistemáticos e objetivos de descrição do conteúdo das mensagens, indicadores (quantitativos ou não) que permitam a inferência de conhecimentos relativos às condições de produção/recepção (variáv eis inferidas) destas mensagens.

\section{RESULTADOS E DISCUSSÃO}

Neste item serão tecidos comentários a respeito das principais disposições contidas na Lei Federal no 12.305/2010, bem como será apresentada a realidade encontrada na implementação de citada norma jurídica no Município de Rio Pomba/MG.

A Lei no 12.305/2010 considera os resíduos sólidos como sendo material, substância, objeto ou bem descartado resultante de atividades humanas em sociedade, a cuja destinação final se procede, se propõe proceder ou se está obrigado a proceder, nos estados sólido ou semissólido, incluindo-se os gases contidos em recipientes e líquidos cujas particularidades tornem inviável o seu lançamento na rede pública de esgotos ou em corpos d'água. 
A destinação final possui um conceito distinto da disposição final, considera-se aquela como a destinação de resíduos que inclui a reutilização, a reciclagem, a compostagem, a recuperação e o aproveitamento energético ou outras destinações admitidas pelos órgãos competentes, com a finalidade de evitar danos ou riscos à saúde pública e à segurança e a minimizar os impactos ambientais adversos. Disposição final é a distribuição ordenada de rejeitos em aterros, observando normas operacionais específicas de modo a evitar danos ou riscos à saúde pública e à segurança e a minimizar os impactos ambientais adversos.

Como se pode perceber, a destinação final inclui a reciclagem que é o processo de transformação dos resíduos sólidos envolvendo a alteração de suas propriedades físicas, físicoquímicas ou biológicas, com vis tas à transformação em insumos ou novos produtos; e a reutili zação significa o processo de aproveitamento dos resíduos sólidos sem sua transformação biológica, física ou físico-química.

A disposição final trata dos rejeitos, que são os resíduos sólidos que depois de esgotadas todas as possibilidades de tratamento e recuperação por processos tecnológicos disponíveis e economicamente viáveis, não apresentem outra possibilidade que não a disposição final ambientalmente adequada.

A PNRS apresentou inovações importantes, podendo ser citadas a logística reversa e a coleta seletiva. A logística reversa visa a coleta e a restituição dos resíduos sólidos ao setor empresarial, para reaproveitamento, em seu ciclo ou em outros ciclos produtivos, ou outra destinação final ambientalmente adequada. A coleta seletiva é o sistema pel o qual se recolhem os resíduos sólidos previamente separados conforme sua constituição ou composição.

A lei também inclui no conceito de geradores de resíduos sólidos o consumidor. Assim, não só as empresas possuem obrigações no que se refere aos resíduos sólidos, mas também as pessoas que gerem resíduos como destinatárias finais de bens ou serviços.

Outro ponto a ser destacado na PNRS se refere aos princípios elencados na mesma. Entende-se por princípios o núcleo do sistema normativo, ou seja, o que há de mais importante no aparato jurídico. Cabem ser citados os seguintes: a) a prevenção e a precaução; b) o poluidorpagador e o protetor-recebedor; c) o desenvolvimento sustentável; d) a ecoeficiência; e) o reconhecimento do resíduo sólido reutilizável e reciclável como um bem econômico e de valor social, gerador de trabalho e renda e promotor de cidadania, e f) o direito da sociedade à informação e ao controle social.

O princípio da prevenção baseia-se na obrigação de evitar a consumação de danos ao meio ambiente, prejuízos estes que são conhecidos pelas autoridades competentes. Pelo princípio da precaução busca-se evitar danos sérios ou irreversíveis ao ambiente, quando não exista certeza científica sobre os seus malefícios.

O princípio do poluidor-pagador impõe uma obrigação de indenização ao poluidor pelos prejuízos causados, e o do protetor-recebedor concede o direito a um incentivo por aqueles que exerçam atividades de proteção do meio ambiente.

Já o desenvolvimento sustentável, significa o uso dos bens e recursos naturais de forma a atender as gerações atuais sem prejudicar as vindouras.

A ecoeficiência se configura na compatibilização entre o fornecimento, a preços competitivos, de bens e serviços qualificados que satisfaçam as necessidades humanas e tragam qualidade de vida e a redução do impacto ambiental e do consumo de recursos naturais a um nível, no mínimo, equivalente à capacidade de sustentação estimada do planeta. 
Lado outro, foram traçadas as seguintes finalidades, dentre outras: a) proteção da saúde pública e da qualidade ambiental; b) não geração, redução, reutilização, reciclagem e tratamento dos resíduos sólidos, bem como disposição final ambientalmente adequada dos rejeitos; c) estímulo à adoção de padrões sustentáveis de produção e consumo de bens e serviços; d) adoção, desenvolvimento e aprimoramento de tecnologias limpas como forma de minimizar impactos ambientais; e) incentivo à indústria da reciclagem; f) universalização da prestação dos serviços públicos de limpeza urbana e de manejo de resíduos sólidos, e g) prioridade, nas aquisições e contratações governamentais para produtos reciclados e recicláveis.

Pode-se dizer que a principal finalidade da Lei de Resíduos Sólidos é a proteção à saúde ambiental, uma vez que a disposição inadequada dos resíduos ocasiona variados problemas de saúde pública. Com efeito, é sabido que para se ter uma vida salubre é imprescindível um ambiente equilibrado.

Para alcançaros objetivos inscritos na PNRS, merecem ser citadas as seguintes ferramentas: a) os planos de resíduos sólidos; b) a coleta seletiva e os sistemas de logística reversa; c) o incentivo à criação e ao desenvolvimento de cooperativas ou de outras formas de associação de catadores de materiais reutilizáveis e recicláveis; d) a educação ambiental; e) os incentivos fiscais, financeiros e creditícios, e f) os conselhos de meio ambiente e, no que couber, os de saúde.

É relevante o instrumento de incentivo aos catadores de materiais reutilizáveis e recicláveis, uma vez que por meio dele tais profissionais podem ser inseridos dignamente na sociedade, em virtude do reconhecimento do valor econômico de alguns tipos de resíduos.

Ainda deve ser registrada a educação ambiental, a qual deve estar presente em todos os níveis e modalidades de ensino, para que sejam construídos valores voltados para o atingimento de resultados garantidores do meio ambiente equilibrado e para o desenvolvimento sustentável.

Cabem ser ressaltados os planos de resíduos sólidos nacional e estaduais, em cujo conteúdo devem estar inseridas metas para a eliminação e recuperação de lixões, mediante a inclusão social e a emancipação econômica de catadores de materiais reutilizáveis e recicláveis.

Conforme se pode vislumbrar, a norma jurídica prevê o fim dos lixões, mas não se esquece do pessoal que exerce atividades laborais relacionadas aos resíduos sólidos, eis que prevê a emancipação econômica dos mesmos.

Também deve ser citado o plano municipal de gestão integrada de resíduos sólidos, cuja elaboração é condição para os Municípios terem acesso a recursos da União, ou por ela controlados, destinados a empreendimentos e serviços relacionados à limpeza urbana e ao manejo de resíduos sólidos.

Este plano, acertadamente, deve prever programas e ações para a participação dos grupos interessados, em especial das cooperativas ou outras formas de associação de catadores de materiais reutilizáveis e recicláveis formadas por pessoas físicas de baixa renda e mecanismos para a criação de fontes de negócios, emprego e renda, mediante a valorização dos resíduos sólidos.

Tais disposições são notáveis, eis que buscam a inserção dos catadores de baixa renda, a partir do já citado reconhecimento do valor econômico dos resíduos.

A Lei no 12.305/2010 classificou os resíduos, primeiramente, quanto à orig em: a) resíduos domiciliares: os originários de atividades domésticas em residências urbanas; b) resíduos de limpeza urbana: os originários da varrição, limpeza de logradouros e vias públicas e outros serviços de limpeza urbana; c) resíduos sólidos urbanos: os englobados nas descrições acima; d) resíduos 
de estabelecimentos comerciais e prestadores de serviços: os gerados nessas atividades, com algumas exceções; e) resíduos dos serviços públicos de saneamento básico: os gerados nessas atividades, com exceções; f) resíduos industriais: os gerados nos processos produtivos e instalações industriais; g) resíduos de serviços de saúde: os gerados nos serviços de saúde, conforme definido em regulamento; h) resíduos da construção civil: os gerados nas construções, reformas, reparos e demolições de obras de construção civil, incluídos os resultantes da preparação e escavação de terrenos para obras civis; i) resíduos agrossilvopastoris: os gerados nas atividades agropecuárias e silviculturais, incluídos os relacionados a insumos utilizados nessas atividades; j) resíduos de serviços de transportes: os originários de portos, aeroportos, terminais alfandegários, rodoviários e ferroviários e passagens de fronteira, e k) resíduos de mineração: os gerados na atividade de pesquisa, extração ou beneficiamento de minérios.

A outra classificação se refere à periculosidade, sendo os resíduos divididos em: a) resíduos perigosos: aqueles que, em razão de suas características de inflamabilidade, corrosividade, reatividade, toxicidade, patogenicidade, carcinogenicidade, teratogenicidade e mutagenicidade, apresentam significativo risco à saúde pública ou à qualidade ambiental, de acordo com lei, regulamento ou norma técnica; b) resíduos não perigosos: aqueles não enquadrados na descrição acima.

Disposição igualmente relevante é a de que o poder público, o setor empresarial e a coletividade são responsáveis pela efetividade das ações voltadas para assegurar a observância da Política Nacional de Resíduos Sólidos.

Na hipótese de geração de resíduos domiciliares, o gerador terá cessada a responsabilidade pelos resíduos com a disponibilização adequada para a coleta ou, com a devolução no caso de logística reversa.

A lei ainda criou a responsabilidade compartilhada pelo ciclo de vida dos produtos, que envolve os fabricantes, importadores, distribuidores e comerciantes, os consumidores e os titulares dos serviços públicos de limpeza urbana e de manejo de resíduos sólidos.

Esta responsabilidade é de grande valia, eis que visa propiciar que as atividades produtivas alcancem eficiência e sustentabilidade e incentivar as boas práticas de responsabilidade socioambiental.

No que tange às embalagens, elas devem ser fabricadas com materiais que propiciem a reutilização ou a reciclagem, cabendo garantir que elas sejam restritas em volume e peso às dimensões requeridas à proteção do conteúdo e à comercialização do produto.

A PNRS preceitua a obrigação de estruturar e implementar o sistema de logística reversa, mediante retorno dos produtos após o uso pelo consumidor, aos fabricantes, importadores, distribuidores e comerciantes de agrotóxicos, de pilhas e baterias, de pneus, de óleos lubrificantes, de lâmpadas fluorescentes e de produtos eletroeletrônicos.

Referido sistema deve ser estendido a produtos comercializados em embalagens plásticas, metálicas ou de vidro e aos demais produtos e embalagens, considerando, prioritariamente, o grau e a extensão do impacto à saúde pública e ao meio ambiente dos resíduos gerados.

Cumpre aos consumidores efetuarem a devolução após o uso, aos comerciantes ou distribuidores, dos produtos e das embalagens citadas. Já os comerciantes e distribuidores deverão efetuar a devolução aos fabricantes ou aos importadores. $E$ estes darão destinação ambientalmente adequada aos produtos e às embalagens reunidos ou devolvidos, sendo o rejeito encaminhado para a disposição final ambientalmente adequada. 
Concernente à coleta seletiva, compete gizar que sempre que estabelecido este aparato pelo plano municipal de gestão integrada de resíduos sólidos, os consumidores são obrigados a acondicionar adequadamente e de forma diferenciada os resíduos sólidos gerados e a disponibilizar adequadamente os resíduos sólidos reutilizáveis e recicláveis para coleta ou devolução. De forma apropriada, foi previsto que o poder público municipal pode instituir incentivos econômicos para os consumidores que participarem de referido sistema.

Foi anotado que o poder público deverá estabelecer políticas indutoras e linhas de financiamento para atender, prioritariamente, às iniciativas de: a) prevenção e redução da geração de resíduos sólidos no processo produtivo; b) desenvolvimento de produtos com menores impactos à saúde humana e à qualidade ambiental em seu ciclo de vida; c) implantação de infraestrutura física e aquisição de equipamentos para cooperativas ou outras formas de associação de catadores de materiais reutilizáveis e recicláveis formadas por pessoas físicas de baixa renda; d) desenvolvimento de projetos de gestão dos resíduos sólidos de caráter intermunicipal ou regional, e) estruturação de sistemas de coleta seletiva e de logística reversa.

Nesta direção, a União, os Estados, o Distrito Federal e os Municípios, no âmbito de suas competências, poderão instituir normas com o objetivo de conceder incentivos fiscais, financeiros ou creditícios a: a) indústrias e entidades dedicadas à reutilização, ao tratamento e à reciclagem de resíduos sólidos produzidos no território nacional; b) projetos relacionados à responsabilidade pelo ciclo de vida dos produtos, prioritariamente em parceria com cooperativas ou outras formas de associação de catadores de materiais reutilizáveis e recicláveis formadas por pessoas físicas de baixa renda, e c) empresas dedicadas à limpeza urbana e a atividades a ela relacionadas.

A Política Nacional explicitou a proibição das seguintes formas de destinação ou disposição final de resíduos sólidos ou rejeitos: a) lançamento em praias, no mar ou em quaisquer corpos hídricos; b) lançamento in natura a céu aberto, excetuados os resíduos de mineração, e c) queima a céu aberto ou em recipientes, instalações e equipamentos não licenciados para essa finalidade.

Por seu turno, foram proibidas nas áreas de disposição final de resíduos ou rejeitos, as seguintes atividades: a) utilização dos rejeitos dispostos como alimentação; b) catação; c) criação de animais domésticos, e d) fixação de habitações temporárias ou permanentes.

Tais vedações têm o objetivo de preservar o meio ambiente e a saúde pública, a fim de se garantir um ambiente ecologicamente equilibrado, em atendimento ao princípio da dignidade da pessoa humana.

Ainda foi proibida a importação de resíduos sólidos perigosos e rejeitos, bem como de resíduos sólidos cujas características causem dano ao meio ambiente, à saúde pública e animal e à sanidade vegetal, ainda que para tratamento, reforma, reuso, reutilização ou recuperação.

Esta também é uma importante determinação, uma vez que ao não se permitirem tais importações, trará como consequências a redução no consumo destes materiais, bem como de sua possível disposição ou destinação final irregular.

A regra jurídica previu a responsabilidade civil objetiva pela reparação dos danos causados, a qual independe da demonstração de culpa, por parte de quem por ação ou omissão descumprir os seus preceitos, além de imputar aos infratores as sanções previstas na lei de crimes ambientais.

Ainda constou-se o prazo de até 4 (quatro) anos após a publicação da PNRS para a disposição final ambientalmente adequada dos rejeitos, ou seja, até agosto de 2014 deveriam ter sido eliminados todos os lixões. 
Pois bem. Com a finalidade de se evidenciarem as particularidades da implementação da Política Nacional de Resíduos Sólidos no Município de Rio Pomba/MG, foram realizadas pesquisas de trabalhos acadêmicos sobre o referido tema em outras cidades. Contudo, os dados obtidos mostraram-se incipientes.

No Município de Rio Pomba/MG os resíduos sólidos são tratados, diretamente, pela Secretaria de Meio Ambiente, a qual possui as seguintes atribuições: cuidar da coleta dos resíduos sólidos e do aterro controlado, zelar pelas praças e jardins, podar e cortar as árvores e arbustos da área urbana, fazer o plantio de mudas na área urbana, realizar campanhas de educação e conscientização ambiental, presidir o Conselho Municipal de Defesa do Meio Ambiente de Rio Pomba/MG - CODEMA, criar o plano de manejo da área de proteção ambiental, coordenar a Recuperação de Áreas Degradadas (RAD) e implementar a coleta seletiva no município.

Da mesma forma, o Departamento de Obras do Município e o Conselho Municipal de Defesa do Meio Ambiente de Rio Pomba/MG (CODEMA) atuam efetivamente no que tange aos resíduos sólidos.

Até o ano de 1998, o Município de Rio Pomba/MG possuía um local destinado à deposição dos resíduos sólidos e rejeitos, localizado no Distrito Industrial - no lugar denominado Bomtempo, sendo que a partir de 1999 foi instituída a usina de compostagem e reciclagem, que perdurou até 2007, quando houve a substituição por um aterro controlado.

Aterro controlado é um sistema de contenção dos resíduos que, após ser lançado no depósito, é coberto por uma camada de solo. Tal aparato minimiza o mau cheiro e o impacto visual, além de evitar a proliferação de vetores. Contudo, não ocorre à impermeabilização de base, o que evitaria que os materiais contaminassem o solo e o lençol freático, nem há sistema de tratamento do chorume ou do biogás.

De fato, o citado Município possui um terreno para o recebimento dos resíduos, classificado como aterro controlado, localizado no lugar denominado Monte Alegre - comunidade da Serrinha, com a área de 9,68 hectares.

Contudo, este local está com a capacidade de recebimento dos rejeitos e resíduos esgotada, sendo que foram discutidas as seguintes alternativas: a aquisição de outra área para a criação de uma usina de compostagem e reciclagem em substituição ao aterro; o envio dos dejetos para um aterro particular da cidade de Juiz de Fora/MG, ou a criação de um consórcio com o município de Ubá/MG, sendo que as partes não chegaram a um acordo com relação ao município que seria o destinatário dos resíduos e rejeitos.

Como se findou o prazo, no dia 02 de agosto de 2014, para que fosse implementada a disposição final ambientalmente adequada, a municipalidade decidiu proceder ao envio dos dejetos para um aterro particular da cidade de Juiz de Fora/MG, o qual é devidamente licenciado pelos órgãos ambientais competentes.

Assim, o aterro controlado de Rio Pomba/MG está servindo apenas de transbordo para o recolhimento e posterior envio dos rejeitos e resíduos para o Município de Juiz de Fora/MG, o que é feito através de caçambas acopladas nos caminhões que fazem o transporte.

Para os resíduos serem transportados até o aterro de Rio Pomba/MG, são utilizados dois caminhões: um Chevrolet, ano 90, equipado com caçamba basculante com alongamento e abertura completa da tampa traseira, e um Ford, ano 92, com caçamba basculante com alongamento. $\mathrm{O}$ alongamento na caçamba tem a função de comportar maior capacidade de carga e evitar o transbordo durante a coleta. 
Estes caminhões percorrem, cada um, 70 (setenta) $\mathrm{Km}$ de perímetro urbano diário para realizar a coleta do lixo, totalizando 140 (cento e quarenta) Km, o que ocasiona o dispêndio mensal de $R \$ 3.036,32$ (três mil e trinta e seis reais e trinta e dois centavos). Já as despesas mensais coma manutenção dos veículos e outros materiais (vassouras, sacos de lixo e materiais de limpeza) atingem em média, respectivamente, $\mathrm{R} \$ 1.149,04$ (mil cento e quarenta e nove reais e quatro centavos) e $\mathrm{R} \$ 600,00$ (seiscentos reais).

No referido município trabalham diretamente com os resíduos sólidos 6 (seis) garis, 1 (um) encarregado pelos garis, 2 (dois) motoristas de caminhão, 2 (dois) operadores de máquina, 3 (três) ajudantes gerais, 1 (um) adolescente participante do programa pró-criança e 1 (um) vigia no aterro controlado.

Em cada caminhão laboram na coleta diária um motorista e três garis. A prefeitura municipal fornece ao pessoal que realiza a limpeza urbana os seguintes equipamentos de proteção individual (EPI): uniforme, botas e luvas. O valor médio percebido por estes profissionais é de um salário mínimo mensal, acrescido do adicional de insalubridade de $40 \%$ (quarenta por cento) sobre o salário mínimo.

O gasto médio mensal com o pagamento de salários do pessoal supracitado é de $\mathrm{R} \$ 13.900,00$ (treze mil e novecentos reais).

A quantidade de resíduos sólidos e de rejeitos coletados diariamente é de aproximadamente 10 (dez) toneladas, sendo o recolhimento realizado de segunda-feira a sábado.

O Município implantou o sistema de coleta seletiva, que é realizado às terças e sextasfeiras, das 12 às 15 horas.

Outro passo importante foi a criação do plano municipal de gerenciamento de resíduos sólidos e a confeç̧ão do plano municipal de saneamento básico. Este plano engloba o abastecimento de água, o esgotamento sanitário, a limpeza urbana e manejo de resíduos sólidos e a drenagem e manejo das águas pluviais urbanas.

Com relação aos resíduos hospitalares, de qualquer natureza, os mesmos não sãoleva dos para o aterro de Juiz de Fora/MG, mas encaminhados para incineração na cidade de Ubá/MG, cujos trabalhos são realizados por uma empresa especializada.

Também é realizada a educação ambiental nas escolas municipais, sendo os alunos orientados e incentivados por propostas como a de "troque vinte garrafas pet por uma revista infantil (gibi)", além da sala que mais coletar garrafas pet no ano ser premiada com uma viagem.

O município de Rio Pomba/MG é contemplado pelo incentivo financeiro do ICMS Ecológico, em decorrência da conservação da Área de Proteção Ambiental que possui 8.749,95ha, na qual foi proibida qualquer atividade econômica, exceto a produção sustentável de produtos não madeireiros.

Os catadores de materiais recicláveis e reaproveitáveis são incentivados por meio de acordo com a municipalidade no sentido de efetuarem a coleta antes da passagem do pessoal do poder público, a fim de que possam promover a emancipação econômica.

Além disso, ocorreram tentativas na criação da associação dos colabora dores ambientais de materiais recicláveis e reaproveitáveis de Rio Pomba - ACOAMARP, sendo que tal intento não foi levado adiante, em virtude da falta de interesse por parte de referidos colaboradores (catadores). 
Outras atividades consideráveis concretizadas pela Municipalidade foram: a contratação de empresas, sem qualquer ônus para o município, para realizarem o recolhimento e disposição adequada de pilhas e baterias e o lixo eletrônico do município, além de uma empresa que recolhe o óleo de cozinha e o troca por detergente.

\section{CONCLUSÕES}

Pode-se afirmar que o tema dos resíduos sólidos, não obstante suas graves consequências para a saúde ambiental, nem sempre recebe o merecido tratamento. De fato, muitos municípios brasileiros ainda depositam os resíduos em vazadouros a céu aberto (lixões) ou em áreas alagadas ou alagáveis.

Como se não bastasse, os estudos locais a respeito da situação dos resíduos sólidos nos Municípios ainda são embrionários, sendo necessário realizar trabalhos nesta área, em função dos seus consectários, quais sejam, a qualidade ambiental e a saúde pública.

Os dados coletados mostraram que, apesar do Município de Rio Pomba/MG estar buscando atender as dis posições contidas na Política Nacional de Resíduos Sólidos, ainda há muito a ser feito.

Com efeito, apenas para ilustrar, o Município não elaborou o plano municipal de gestão integrada de resíduos sólidos, o qual é uma condição imposta pela lei para o recebimento de recursos da União, ou por ela controlados, destinados a empreendimentos e serviços relacionados à limpeza urbana e ao manejo de resíduos sólidos.

O citado Município precisa avançar quanto à criação da associação dos catadores de materiais reutilizáveis e recicláveis, eis que foi prevista a emancipação econômica dos mesmos, por meio de incentivos.

Por fim, os gestores municipais devem ter a consciência de que a questão ambiental é diretamente relacionada à saúde pública, não podendo deixar de dar cumprimento às regras contidas na Carta Magna e nos demais dispositivos legais, no que se refere à saudável qualidade de vida.

\section{REFERÊNCIAS BIBLIOGRÁFICAS}

1. ANTUNES, P. B. Competências Constitucionais em Matéria Ambiental. In: . Direito Ambiental. 13.ed. Rio de Janeiro: Lumen Juris, 2011. p. 89-106.

2. BARDIN, L. Análise de conteúdo. Lisboa: Edições 70, 1997. p. 21-42.

3. BRASIL. Constituição (1988). Constituição da República Federativa do Brasil. 15.ed. São Paulo: Saraiva, 2014. 500 p.

4.

Lei $n$ - 6.938, de 31 de agosto de 1981. Dispõe sobre a Política Nacional do Meio Ambiente, seus fins e mecanismos de formulação e aplicação, e dá outras providências. Disponível em: <https://www.planalto.gov.br/ccivil_03/Leis/L6938org.htm> . Acesso em 08 mar. 2014.

5.

Lei $\mathbf{n}$ 12.305, de 2 de Agosto de 2010. Institui a Política Nacional de Resíduos Sólidos; altera a Lei no 9.605, de 12 de fevereiro de 1998; e dá outras providências. Disponível em: <http://www.planalto.gov.br/ccivil_03/_ato2007-2010/2010/lei//12305 .htm>. Acesso em 08 mar. 2014. 
6. _. Instituto Brasileiro de Geografia e Estatística (IBGE/2010). Diretoria de Pesquisas DPE - Coordenação de População e Indicadores Socias - COPIS. Disponível em: <http://www.cidades.ibge.gov.br/painel/painel.php?lang=\&codmun=315580\&search=minas gerais|rio-pomba|infograficos:-dados-gerais-do-municipio>. Acesso em 15 out. 2015.

7. KELSEN, H. O Direito e o Estado. In: . Teoria Geral do Direito e do Estado. 3.ed. São Paulo: Martins Fontes, 1998. p. 261-298.

8. MATIAS-PEREIRA, J. Cultura nas organizações públicas. In: . Curso de administração pública: foco nas instituições e ações governamentais. 3.ed. São Paulo: Atlas, 2010. p. 78-81.

9. MILARÉ, É. Fundamentos Constitucionais da Proteção Ambiental. In: Direito do Ambiente. 4.ed. São Paulo: Revista dos Tribunais, 2005. p. 180-265.

10. SARAVIA, E. Introdução à teoria da política pública. In: SARAVIA, E.; FERRAREZI, E. (Orgs.). Políticas Públicas. Brasília, ENAP, v.2, 2006. p. 21-42.

11. SILVA, J. A. Direito Ambiental Constitucional. 7.ed. São Paulo: Malheiros Editores, 2009. 347 p.

12. VERGARA, S. C. Projetos e relatórios de pesquisa em administração. 12.ed. São Paulo: Atlas, 2010. $94 \mathrm{p}$. 